\title{
Labial fusion causing urinary incontinence: comment
}

\author{
Montasser A. Mahran • Nicholas Oligbo
}

Published online: 8 July 2011

(C) The International Urogynecological Association 2011

\section{Dear Editor,}

We read with interest the recent case report by Dirim and Hasirci, which concluded that dividing the labial fusion can completely alleviate all urinary symptoms [1]. Indeed, there is a body of evidence to support the surgical division of labial adhesion to treat the pseudo-incontinence in postmenopausal women [2].

In current practice, usually the regular vaginal examination is not performed in routine follow-up visits, which may lead to under-diagnosis of such cases. The lesson is clear: regular examination is crucial to provide good medical care.

In our experience we had a similar case, and division of adhesions did help to alleviate the symptoms of retention and recurrent urine infection, but not the stress urinary incontinence, as the authors addressed in their case report. It will be useful if the authors provide a logical explanation for the relation between dividing the labial adhesion and the cure of stress urinary incontinence. Also, it is important to emphasis the local application of oestrogen creams following division as this may help in preventing further recurrence [3].

\section{References}

1. Dirim A, Hasirci E (2011) Labial fusion causing urinary incontinence and recurrent urinary tract infection in a postmenopausal female: a case report. Int Urogynecol J 22:119-120. doi:10.1007/ s00192-010-1205-2

2. Palla L, De Angelis B, Lucarini L, Spallone D, Palla G, Cervelli V (2010) A case of labial fusion and urinary pseudo-incontinence in an elderly woman. A surgical treatment and a review. Eur Rev Med Pharmacol Sci 14(5):491-493

3. Parkinson DJ, Alderman B (1984) Vulval adhesions causing urinary incontinence. Postgrad Med J 60(707):634-635

An author's reply to this comment is available at doi 10.1007/s00192011-1497-x.

\footnotetext{
M. A. Mahran $\cdot$ N. Oligbo

James Paget University Hospital,

Norfolk, UK

M. A. Mahran ( $\square)$

James Paget University Hospital,

Great Yarmouth NR31 6LA, UK

e-mail: montasser@doctors.org.uk
} 